\title{
Modeling sediment deposition from marine outfall jets
}

\author{
A. Terfous ${ }^{\text {a }}$, S. Chiban ${ }^{\text {b }, ~ A . ~ G h e n a i m ~}{ }^{\text {a }}$ \\ ${ }^{\text {a }}$ Fluid Mechanics, ICUBE Laboratory, INSA Strasbourg Graduate School of Science and \\ Technology, Strasbourg, France. \\ ${ }^{\mathrm{b}}$ Civil Engineering Department, Tishreen University, Latakia, Syria.
}

\begin{abstract}
This paper presents a two-dimensional model to study the sediment deposition from marine outfall jets. The introduced unidirectional coupling (fluid-sediment) is an appropriate choice in the case of low-concentrated particle-laden jets such as municipal wastewater discharge, where the concentration of particles is small enough and does not affect the hydrodynamic development of the jet in the nearfield. The sedimentation model takes advantage of the preferential concentration phenomenon. The deposition criterion states that the deposition of sediments begins when the vertical component of the entrainment velocity becomes smaller than the settling velocity. Once the deposition process begins, it is controlled by the settling velocity, entrainment velocity, volume flux, and sediment concentration. The deposition along the jet trajectory is expressed by an ordinary differential equation coupled with the liquid phase equations. Experiments of Lane-Serff and Moran (2005), Cuthbertson and Davies (2008) and Lee (2010), chosen from bibliography, are used to validate the model. These experiments cover the cases of horizontal and inclined buoyant jets in stationary ambient, horizontal buoyant jets in co-flow current and non-buoyant horizontal jets in stationary ambient. Good agreement between the experiments and the obtained simulations is revealed.
\end{abstract}

\section{Keywords}

Turbulent flow; Suspended sediment; Mathematical models; Marine outfall jets; Deposition

\section{Introduction}

Wastewater is an important source of anthropogenic pollution in coastal waters and the suspended solids present a significant part of this pollution [1, 2, 3]. For guidance, the variation interval of the concentration of Total Suspended Solids (TSS) in the raw municipal wastewater (The values indicated are the values after the preliminary treatment "screening, grit removal, flotation") is from 150 to $500 \mathrm{mg} / 1$ in France [4]. However, the European Directive 91/271/EEC, determines the requirements for discharges from the secondary treatment as $35 \mathrm{mg} / \mathrm{l}$ of TSS or a minimum percentage of reduction of $90 \%$ in relation to the TSS load of the influent.

The study of suspended solids deposition from low concentrated particles-laden jets as municipal wastewater discharge has been performed for only few scenarios in nonstratified ambient. Neves and Fernando [5] performed an experimental study with dimensional analysis on the deposition of particles from vertical round jets in stationary ambient. Ernst et al. [6] developed a theoretical model for deposition from vertical jets and plumes. McLarnon [7] performed a detailed experimental study to investigate the sedimentation from horizontal buoyant jets in stationary ambient. Bleninger and Carmer [8] performed an experimental study followed by an analytical solution for the deposition from horizontal nonbuoyant round 
jets in stationary ambient. Lane-Serff and Moran [9] performed an experimental study and developed an integral model for deposition from horizontal and inclined buoyant round jets in stationary ambient. Cuthbertson and Davies [10] performed an experimental study with scaling arguments on the deposition from horizontal buoyant round jets in stationary and coflowing ambient. Li [11] studied experimentally the deposition from horizontal buoyant jets in stationary ambient and adopted a Lagrangian approach to model the phenomenon. Cuthbertson et al. [12] performed an experimental study on deposition from plane buoyant jets in stationary ambient followed by a Computational Fluid Dynamics (CFD) modelling. Lee [13] performed an experimental study followed by particle-tracking model in addition to CFD modelling in order to study the deposition from horizontal nonbuoyant round jets in stationary ambient.

The common point between these research works is considering the concentration of solid particles small enough in the discharge so that the presence of these particles has no significant influence on the jet trajectories over a wide range of forcing conditions. This concentration criterion is defined by Cuthbertson and Davies [10] as a volumetric source concentration of $(\sim 0.1 \%)$; while Lane-serff and Moran [9] indicated that a concentration of 10 $\mathrm{gr} / 1$ of solid particles has negligible impact on the flow. Other common considerations for deposition in the nearfield are considering the solid particles noncohesive, and monodisperse having the same size and shape and thus having one terminal fall velocity $w_{s}$ which is the velocity value for the ambient fluid density [8, 9, 10, 12]. However, Cuthbertson et al. [12] studied numerically the dependence of $w_{s}$ upon local fluid density and compared a $w_{s}$ value that varied with the local fluid density with a constant $w_{s}$ value for the ambient fluid density and found that the two cases give indistinguishable deposition profiles due to the rapid dilution of the buoyant jet following release. Finally, all the above experiments and simulations consider that the upper surface of the receiving ambient is free and the seabed is considered as flat and horizontal solid boundary.

The objective of this work is to present a simple model that accurately predicts the deposition from low-concentrated particle-laden turbulent jets in different scenarios. Our proposed model is a Lagrangian model that takes advantage of the preferential concentration phonemene. The unidirectional coupling (fluid-sediment) is used in the modeling because the concentration of solid particles in the municipal wastewater discharge is small enough and does not affect the hydrodynamic developement of the jet. The obtained model is validated using the results of experiments done by Lane-Serff and Moran [9], Cuthbertson and Davies [10] and Lee [13].

\section{The hydrodynamic model for the nearfield zone}

The high momentum turbulent jet creates a zone of low pressure that aspirates the ambient water. In the case of buoyant jets, the momentum flux, in addition to the buoyancy flux, draw the effluent trajectory. When the jet reaches the free surface or the neutral level, it spreads horizontally creating the surface gravity current. In the case of non-buoyant jets "neutral jet" there is no presence of the buoyancy forces.

In this work, we treat jets in stationary ambient and in presence of coflow current. The velocity vector $V$ is located in the $\mathrm{x}-\mathrm{z}$ plane and it is horizontal or inclined with an angle $\phi$ on the $\mathrm{x}$-axis, so it has two components $u$ and $w$. Considering the coflow current and regarding the absence of other external forces, the jet axis remains in the x-z plane as shown in Figure 1. 


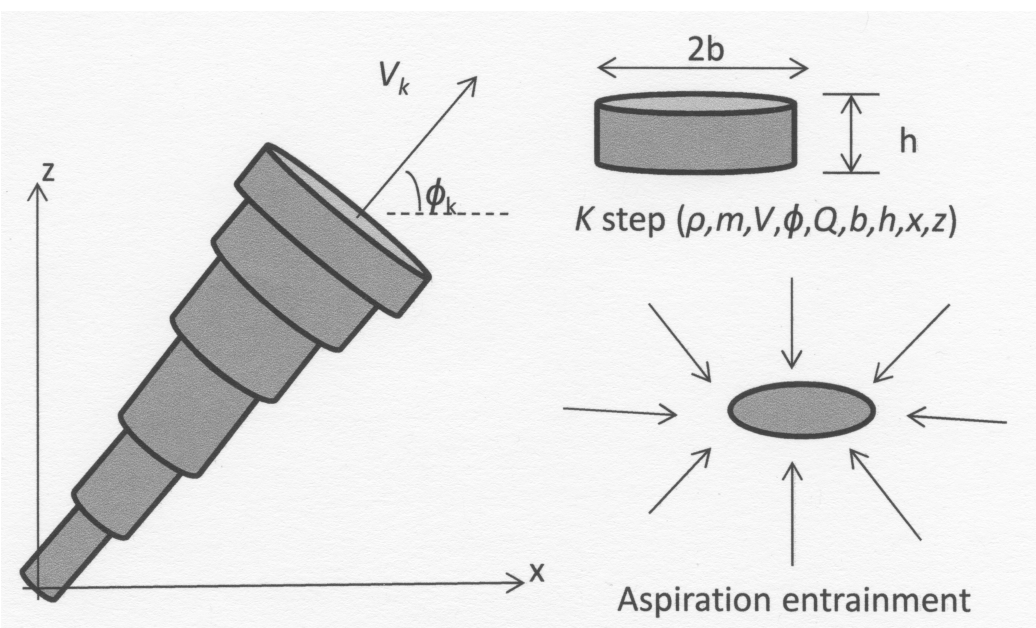

Figure 1. Lagrangian model for buoyant jet in two-dimensional space. Using a fixed time step, we note that the first slices are longer than the last slices because the jet velocity decreases with time.

Integral methods are used to convert the governing partial differential equations (hydrodynamic model presented by the continuity equation and the momentum conservation equation) to a series of ordinary differential equations. These methods were found to produce very good approximations to fluid behaviors as long as the boundary effects do not enter the problem. Integral methods require that appropriate distribution profiles be assumed for velocity, temperature, and concentration. The origins of integral methods are the works of Hirst [14], and Schatzmann [15]. The continuity equation and Navier-Stokes equation are reduced to the following forms [16]:

Conservation of mass

$$
\frac{d m}{d t}=E
$$

where $m$ is the mass and $t$ is the time. Equation (1) indicates that the change in the flow rate within the jet equals to the fluid entrained $E$. The entrainment $E$ can be divided to the aspiration entrainment and forced entrainment. In the stationary ambient, or in a very weak current, the aspiration entrainment (Figure 1) presents the dominant entrainment while the forced entrainment is neglected.

Conservation of scalar product

$$
\frac{d m C}{d t}=C_{a} \frac{d m}{d t}
$$

Where $C$ is the concentration of scalar product in time $t . C_{a}$ is the product concentration in the ambient fluid.

Conservation of momentum along the trajectory

$$
\frac{d m V}{d t}=u_{a} \frac{d m}{d t}+m g \frac{\rho_{a}-\rho}{\rho_{a}}
$$


where $V$ is the jet centerline velocity, $u_{a}$ is the current velocity, $\rho$ is the density in the jet, and $\rho_{a}$ is the ambient density.

In the nearfield modeling, we present a two-dimensional version of the Lagrangian integral model presented by Lee and Cheung [17]. The cross-sectional slice of the jet is considered with the Lagrangian formulation as having a coordinate system that moves with the jet. Integration is with time and the calculation takes place at discrete time steps. The slice that is followed is usually in the shape of a section in a bent cone as shown in Figure 1. Properties within the slice are assumed to be uniform (top-hat profiles) but they vary along the trajectory with time. The size and shape of the slice vary as a result of the plume bending, entrainment, and plume growth. The calculation stops when the jet reaches the free surface (in the case of a buoyant jet) or a prescribed distance (in the case of a horizontal nonbuoyant jet). In the literature, we find different formulas for calculating the entrainment $[17,18,19]$. However, in this work only the aspiration entrainment is considered. This entrainment flux (mass/time) into a slice $(k)$ is the entrainment velocity multiplied by the ambient density and the slice surface

$E_{\alpha_{k}}=V_{e_{k}} \cdot \rho_{a} \cdot 2 \cdot \pi \cdot b_{k} \cdot h_{k}$

The ambient water entrainment velocity $V e$ is proportional to the centreline velocity via the entrainment coefficient $\alpha$. Following Lee and Chu (2003), $\alpha=0.057 . \sqrt{2}$ which is the classical value reported for top-hat profiles in round jets.

$V e=|V|_{r=b}=\alpha V$

$V e$ is the entrainment velocity, $V$ is the centerline velocity, $b$ is the jet half-width, $\alpha$ is the entrainment coefficient and $h$ is the slice length.

In each time step $k$, we calculate the slice mean density $\rho$, mass $m$, velocity $V$, inclination $\phi$, flow $Q$, half width $b$ and length $h$. The slice properties calculation is based on the previous slice properties and the loop stops when $z b 2(k)<z$ sea, where $z b 2(k)$ is the upper boundary of the jet and zsea is the free surface height above the discharge point. In the case of nonbuoyant horizontal jets, the loop stops when $x(k)<x a$, where $x a$ is the prescribed distance from the point source. The model is explained in the following equations [20]. The authors put here briefly the liquid phase equations to avoid repetition. However, the following equations can be revealed from a simple forward discretization of Equations (1), (2), and (3) using a constant time step:

The mass in the new slice

$m_{k+1}=m_{k}+E_{\alpha_{k}} \cdot \Delta t$

The mass difference between the two slices $k$ and $k+1$

$\Delta m_{k}=E_{\alpha_{k}} . \Delta t$

The density in the new slice 
$\rho_{k+1}=\frac{m_{k} \cdot \rho_{k}+\Delta m_{k} \cdot \rho_{a}}{m_{k+1}}$

The horizontal velocity

$u_{k+1}=\frac{m_{k} \cdot u_{k}+\Delta m_{k} u_{a}}{m_{k+1}}$

The vertical velocity

$w_{k+1}=\frac{m_{k} \cdot w_{k}}{m_{k+1}}+\frac{\rho_{a}-\rho_{k+1}}{\rho_{a}} g \Delta t$

The centerline velocity

$V_{k+1}=\sqrt{u_{k+1}^{2}+w_{k+1}^{2}}$

The length of the new slice

$h_{k+1}=V_{k+1} \cdot \Delta t$

The half-width of the new slice

$b_{k+1}=\sqrt{\frac{m_{k+1}}{\rho_{k+1} \cdot \pi \cdot h_{k+1}}}$

The inclination of the jet axis in the new slice,

$\phi_{k+1}=\arctan \left(\frac{w_{k+1}}{u_{k+1}}\right)$

The distance from the source to the new slice along the jet axis

$S_{k+1}=\sum_{k=0}^{k+1} h_{k}$

The coordinates of the center of the upper surface in the new slice

$$
\begin{aligned}
& x_{k+1}=x_{k}+u_{k} \cdot \Delta t \\
& z_{k+1}=z_{k}+w_{k} \cdot \Delta t
\end{aligned}
$$

The coordinates of the boundaries of the upper surface in the new slice (inferior point 1 and high point 2): 


$$
\begin{aligned}
& x b 1_{k+1}=x_{k+1}+b_{k+1} \sin \phi_{k+1} \\
& z b 1_{k+1}=z_{k+1}-b_{k+1} \cos \phi_{k+1} \\
& x b 2_{k+1}=x_{k+1}-b_{k+1} \sin \phi_{k+1} \\
& z b 2_{k+1}=z_{k+1}+b_{k+1} \cos \phi_{k+1}
\end{aligned}
$$

The ambient fluid entrainment into the new slice

$$
E_{\alpha_{k+1}}=\alpha_{k+1} \cdot V_{k+1} \cdot \rho_{a} \cdot 2 \cdot \pi \cdot b_{k+1} \cdot h_{k+1}
$$

The first slice (Slice 0) characteristics can be deduced from the initial conditions of the jet as follows

$(u, w)_{0}=\left(V_{0} \cos \phi_{0}, V_{0} \sin \phi_{0}\right)$

The half width $b_{0}$ and the length $h_{0}$

$(b, h)_{0}=(0.5 D, 0.5 D)$

Where $D$ is the nozzle diameter and $\phi_{0}$ is the initial inclination of the jet.

The initial time step, which is taken as a constant in the calculation

$$
\Delta t=0.1 \cdot \frac{h_{0}}{V_{0}}
$$

The coordinates of the first slice

$(\mathrm{x}, \mathrm{z})_{0}=(0,0)$

For horizontal nonbuoyant jets, this routine can be modified because the vertical velocity $w$ is eliminated from all equations and the calculation stops after the prescribed distance $x a$. In this case, Equation (8) is eliminated because there is no density difference between the two fluids. Equation (10) is eliminated because there is neither initial vertical velocity nor buoyancy forces, and the same for Equations (14), and (17). Basing on these eliminations, Equations (11), (13), (18), and (20) are modified.

\section{The sediment deposition model for the nearfield zone}

The preferential particles concentration in turbulent flow is the formation of concentration inhomogeneity that is related to the fact that the particles, which are more dense than the flow, have the tendency to accumulate in the weak vorticity zones because of the centrifugal force that trains them towards the periphery of the turbulent structures $[21,22,23,24]$. This phenomenon of preferential concentration or correlation between the instantaneous distribution of solid particles and the fluctuations of fluid velocity results in the existence of solid particles agglomerations that move with turbulence big structures.

In turbulent jets, the vorticity is highest in shear layers. In stationary ambient and in the presence of coflow, these shear layers are located at the boundaries of turbulent jets. The 
Digimage tracking measurements of particle-laden buoyant jets discharging into initially stationary ambient and coflowing ambient body, made by Cuthbertson and Davies [10] shows clearly the maximum vorticity located at the jet boundaries. However, in the presence of cross flow, the interaction of the jet momentum results in a complicated turbulent shear flow. Vortices of various kinds are being generated close to the source, in particular a pair of twinvortices in the bent-over phase of the buoyant jet. A simple pair of vortex eyes can be seen [20].

According to these observations, and to the fact that solid particles will accumulate in the low-vorticity areas, two different deposition patterns can be revealed for turbulent free jets in homogenous ambient. The first is for deposition from turbulent jets in stationary and coflow ambient and the second is for deposition from turbulent jets in cross flow. In the context of our study (deposition from low-concentrated particles-laden jets), the first pattern is the one studied so far in the available literature, experimentally and numerically. Depending on the experiments of Lee [13], and the experiments of Bush et al. [25] on particle cloud that initially assumes the form of a turbulent thermal, this pattern results in localized deposition $[13,25]$.

Considering the above researches, we assume that solid particles deposit from the inferior central part of the jet, as Figure 2 shows.

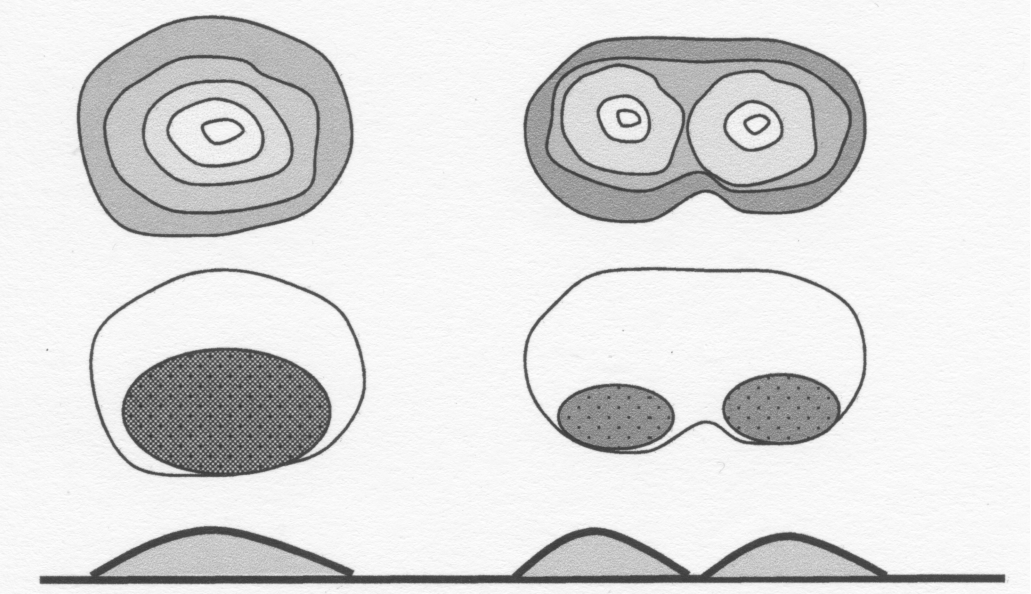

Figure 2. Up- Indicative schema for the vorticity field in the cross-section of turbulent jets in stationary or co-flow ambient (Left), and in cross-flow (Right). Middle- The preferential concentration of solid particles in low vorticity areas, in the inferior parts the jet. Down: Localised deposition (Left) and Ring deposition (Right).

The following hypotheses are made in order to build the sediment deposition model basing on the preferential concentration phenomenon:

1- We consider that the solid particles begin to deposit when their settling velocity is greater than the vertical component of the entrainment velocity

$w_{s}>\alpha_{k} \cdot V_{k} \cdot \cos \phi_{k}$

Thus, the vertical velocity of the solid particle depositing from the jet will be:

$w_{\text {out }}=w_{s}-\alpha_{k} V_{k} \cos \phi_{k}$

We would like to mention that a similar term is used by Lane-Serff and Moran [9]. But $w_{\text {out }}$ adopted in the model of Lane-Serff and Moran [9] is taken on the axis of the 
entrainment velocity, perpendicularly on the jet axis (The criterion Equation (24) is written in this case: $w_{s} . \cos \phi_{k}>\alpha_{k} V_{k}$ ); while in our model we considered the projection, on the z-axis, of the result of the two acting velocities. However, several tests were performed to investigate the effect of the choice of projection axis, in the cases of horizontal buoyant jets and slightly-inclined buoyant jets $\left(17^{\circ}\right.$ and $\left.-15^{\circ}\right)$, we found that in practice, the two choices give very close predictions of the longitudinal deposition, because the criterion is met in a distance too near to the nozzle, where the trajectory does not bent yet under the effect of buoyancy but it still rather horizontal and $\cos \phi_{k} \cong 1$ which makes no difference between the two formulas. However, further investigations on more inclined jets will help in determining which choice is the more convenient in the Lagrangian modeling.

2- The zone of deposition does not spread on all the width of the jet cross-section, but it has a smaller width depends on the ratio between the entrainment velocity and the settling velocity. The greater the settling velocity compared with the entrainment velocity, the bigger the zone of deposition and thus the higher deposition rate and vice versa. In other words, the portion of the cross-section area occupied by the deposition zone is proportional to the ratio of entrainment velocity to settling velocity. For example, in the high-momentum region, the zone of deposition occupies a small portion of the jet crosssection, but in the buoyancy-dominated region, the settling velocity is largely bigger than the entrainment velocity, so the deposition zone occupies almost all the jet cross-section. The portion of the cross-section area occupied by the deposition zone can be described by the parameter $\left(1-\alpha V \cos \phi / w_{s}\right)$. In this way, we do not need to assume a specific geometry of the deposition zone in the cross-section area (that can be ring or circle as Figure 2 shows, or an angular sector as the deposition zone geometry proposed by LaneSerff and Moran [9]). However, Figure 3 shows the evolution of this parameter in a horizontal buoyant jet.

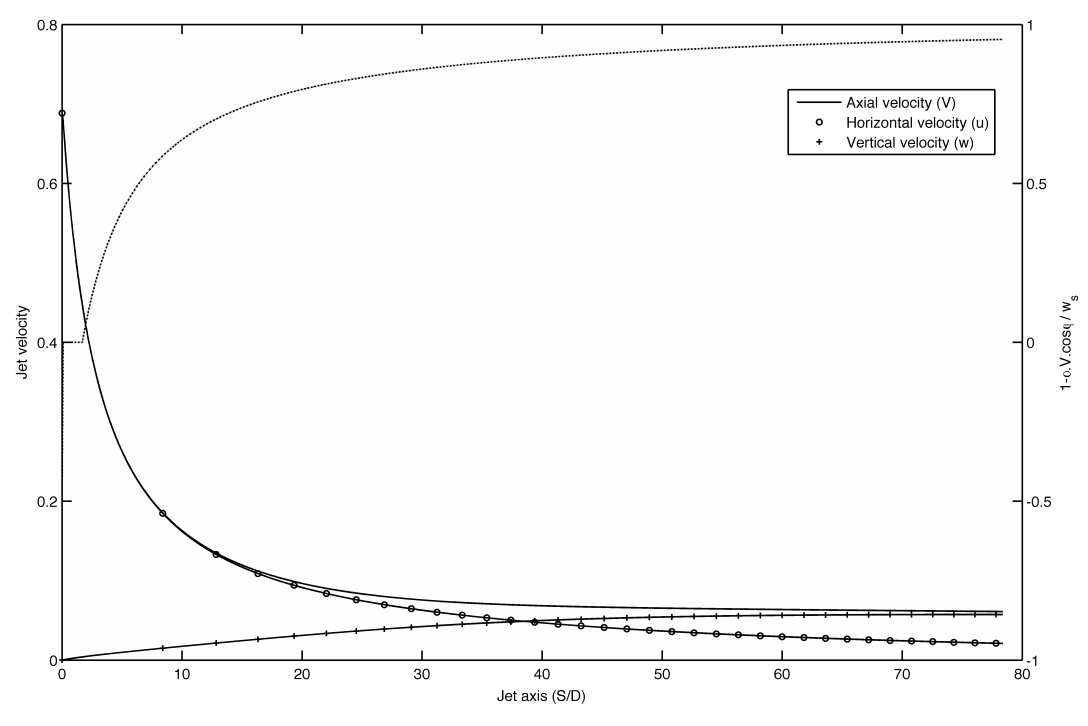

Figure 3. The velocity profile along the jet axis corresponding to experiments of Lee [10] for case 3 in Table.1, in addition to the evolution of the parameter $\left(1-\alpha V \cos \phi / w_{s}\right)$ " the dashed line with the axis on the right". The markers on $(u)$ and $(w)$ profiles are put every 400 step of calculation. 
Considering the fundamental deposition model of Koh and Chang [26] for the settling of barge disposed wastes:

$$
\frac{d P}{d S}=-2 w_{s} C_{p} b(1-\beta)
$$

Where $P$ is the solid flux in the jet; $S$ is the distance along the jet axis, $C p$ is the solid concentration $(C p=P / Q)$ and $\beta$ is a constant taken normally $\beta=0[26,27]$.

The model presented in this study is based on this fundamental model, where the terms are developed to incorporate more general cases. The model is written as follows (the number below the term indicate the number of the formerly-mentioned assumption used to built the term):

$$
\frac{d P}{d S}=-2(\underbrace{w_{s}-\alpha V \cos \phi}_{1}) C_{P} b(\underbrace{1-\frac{\alpha V \cos \phi}{w_{s}}}_{2}) c f
$$

Where $c f$ is a constant that reflects the effect of buoyancy forces in inhibiting the deposition: $c f=1$ in considerably buoyancy-dominated flow $\left(\mathrm{g}_{0}{ }^{\prime}=0.384 \mathrm{~m} / \mathrm{s}^{2}\right.$, approximately, that can correspond to a discharge of an initial density of $1000 \mathrm{~kg} / \mathrm{m}^{3}$ in a milieu of average density of $\left.1040 \mathrm{~kg} / \mathrm{m}^{3}\right)$.

$c f=1.5$ in moderately buoyant-dominated flow $\left(\mathrm{g}_{0}{ }^{\prime}=0.185 \mathrm{~m} / \mathrm{s}^{2}\right.$, approximately, that can correspond to a discharge of an initial density of $1000 \mathrm{~kg} / \mathrm{m}^{3}$ in a milieu of average density of $\left.1020 \mathrm{~kg} / \mathrm{m}^{3}\right)$.

$c f=2$ for nonbuoyant jets.

This parameter is always taken $1(c f=1)$ in the case of presence of coflow.

We will discretize the Equation (27) in a finite difference step forward framework, in order to couple it with the near field model, thus we can get the solid flux in each slice $k$, which enables us to reveal the deposition rate curve along the jet trajectory:

Equation 27 is arranged by replacing $C_{p}$ by $P / Q$ as follows:

$\frac{1}{P} \frac{d P}{d S}=-2\left(w_{s}-\alpha V \cos \phi\right) \cdot \frac{b}{Q} \cdot\left(1-\frac{\alpha V \cos \phi}{w_{s}}\right) \cdot c f$

Better numerical accuracy can be achieved by rearranging Equation (28) using $\frac{1}{P} \frac{d P}{d S}=\frac{d \ln P}{d S}$.

$$
\frac{d \ln P}{d S}=-2\left(w_{s}-\alpha V \cos \phi\right) \cdot \frac{b}{Q} \cdot\left(1-\frac{\alpha V \cos \phi}{w_{s}}\right) \cdot c f
$$

We discretize Equation (29) in a finite difference step forward framework as follows:

$$
\frac{\ln P_{k+1}-\ln P_{k}}{h_{k}}=-2\left(w_{s}-\alpha V_{k} \cos \phi_{k}\right) \cdot \frac{b_{k}}{Q_{k}} \cdot\left(1-\frac{\alpha V_{k} \cos \phi_{k}}{w_{s}}\right) \cdot c f
$$


The formula that is coupled with the fluid phase model and put in the calculation routine becomes:

$$
\ln P_{k+1}=\ln P_{k}-2\left(w_{s}-\alpha V_{k} \cos \phi_{k}\right) \cdot \frac{b_{k}}{Q_{k}} \cdot\left(1-\frac{\alpha V_{k} \cos \phi_{k}}{w_{s}}\right) \cdot c f \cdot h_{k}
$$

\section{Results and discussions}

The cases that we study fall under four distinct categories: Horizontal buoyant jets in stationary ambient (I); Inclined buoyant jets in stationary ambient (II); Horizontal buoyant jets in coflowing ambient (III) and Horizontal nonbuoyant jets in stationary ambient (IV).

These categories are found in the available literature about deposition from buoyant and nonbuoyant jets, which enable us to calibrate and validate the model presented.

We choose to keep the same units of experimental data as stated in the original references for deposition rates in order to demonstrate the different ways and units used in presenting the deposition rate and for the simplicity in comparison when referring to the experiment in its original reference. Particle density function (PDF) in the experiments of Cuthbertson and Davies [10], and gr/m.s for the other experiments.

The proposed model is validated using the data in Table 1. The experiments of Lane-Serff and Moran [9], Cuthbertson and Davies [10] and Lee [13] are used in order to study the deposition from buoyant and non-buoyant jets and validate the proposed model. We demonstrate the jet hydraulic structure; and compare deposition simulation with the experimental results. We would like to mention that the initial form of data taken from the works of Lane-Serff and Moran [9], Cuthbertson and Davies [10], and Lee [13] are experimental points of longitudinal deposition curve, while the initial form of data taken from the work of Bleninger and Carmer [8] is the number of particles deposited in each cell of a grid located on the ground, after a simple treatment of these raw data, we get the longitudinal deposition curve.

Table 1. Experimental data of Lane-Serff and Moran [9], Cuthbertson and Davies [10], and Lee [13] used to calibrate and validate the proposed model.

\begin{tabular}{cccccccccccc}
\hline & & & & & & & \multicolumn{3}{c}{$z_{\text {sea }}$} \\
Category & Case & $\begin{array}{c}\text { Data } \\
\text { source }\end{array}$ & $\begin{array}{c}V_{0} \\
(\mathrm{~m} / \mathrm{s})\end{array}$ & $\begin{array}{c}D \\
(\mathrm{~mm})\end{array}$ & $\begin{array}{c}\rho_{0} \\
\left(\mathrm{~kg} / \mathrm{m}^{3}\right)\end{array}$ & $\begin{array}{c}\rho_{\mathrm{a}} \\
\left(\mathrm{kg} / \mathrm{m}^{3}\right)\end{array}$ & $\begin{array}{c}u_{a} \\
(\mathrm{~m} / \mathrm{s})\end{array}$ & $\begin{array}{c}\phi_{0} \\
\left({ }^{\circ}\right)\end{array} \begin{array}{c}o r \\
x a^{*} \\
(\mathrm{~m})\end{array}$ & $\begin{array}{c}w_{s 0} \\
(\mathrm{~m} / \mathrm{s})\end{array}$ \\
\hline I & 1 & {$[10]$} & 1.04 & 11.5 & 1000 & 1020 & 0 & 0 & 0.747 & 0.0299 \\
II & 2 & {$[9]$} & 0.72 & 5.0 & 998.76 & 1040 & 0 & - & 0.25 & 0.027 \\
III & 3 & {$[10]$} & 1.076 & 11.5 & 1000 & 1020 & 0.038 & 0 & 0.733 & 0.0299 \\
& 4 & {$[13]$} & 0.86 & 6.0 & 997.2 & 997.2 & 0 & 0 & $0.80^{*}$ & 0.0266 \\
\hline & 5 & {$[13]$} & 0.76 & 6.0 & 998.1 & 998.1 & 0 & 0 & $0.80^{*}$ & 0.0193 \\
\hline
\end{tabular}


Lane-Serff and Moran [9] performed experiments on inclined and horizontal round buoyant jets. The experiments were conducted in a rectangular glass tank, with length $1.2 \mathrm{~m}$, width 0.3 $\mathrm{m}$ and depth $0.4 \mathrm{~m}$. The tank was filled to a depth of approximately $0.3 \mathrm{~m}$ with saline solution $\left(\rho_{\mathrm{a}} \sim 1040 \mathrm{~kg} / \mathrm{m}^{3}\right)$. A buoyant sediment-laden plume was created by introducing fresh water (or a weak saline solution) from an outlet of diameter $\mathrm{D}=5 \mathrm{~mm}$ near the bottom of the tank. Two different sieved size fractions of sand were used (fine: $75 \mu \mathrm{m}<\mathrm{d}<150 \mu \mathrm{m}$ ) and (coarse: $75 \mu \mathrm{m}<\mathrm{d}<150 \mu \mathrm{m}$ ). The amount of sand in the fluid source was kept small (less than 10 $\mathrm{gr} / \mathrm{L})$ to minimize its impact on the flow.

The unit of the deposition rate in the experimental results is $\mathrm{gr} / \mathrm{m} . \mathrm{sec}$. To obtain such unit in our model, we entered the initial solid particles concentration as indicated in the experiment $\left(c_{p 0}=10 \mathrm{gr} / \mathrm{L}\right)$, we calculate the initial solid flux $P_{0}=c_{p 0}{ }^{*} Q_{0}(\mathrm{gr} / \mathrm{sec})$, then the model can calculate the deposition from each slice $(\mathrm{gr} / \mathrm{sec})$ and dividing this value by the thickness of each slice $\left(h_{k}\right)$ gives the unit (gr/m.sec).

Cuthbertson and Davies [10] performed experiments on horizontal buoyant jets in stationary and coflowing ambient. The experiments were conducted in a recirculating water channel of length $10.0 \mathrm{~m}$, width $1.0 \mathrm{~m}$, and depth $1.2 \mathrm{~m}$. The channel was filled to a prescribed depth $\mathrm{H}$ $(0.55 \mathrm{~m} \leq \mathrm{H} \leq 0.75 \mathrm{~m})$ with homogeneous saline water of initial density $\left(1020-1040 \mathrm{~kg} / \mathrm{m}^{3}\right)$. Steady uniform ambient flow conditions were established within the channel with depthaveraged velocity $(0.017-0.052 \mathrm{~m} / \mathrm{sec})$. A particle-laden buoyant jet with source density $\left(1000 \mathrm{~kg} / \mathrm{m}^{3}\right)$ was discharged horizontally into the coflowing ambient receiving water through a single round port of internal diameter $\mathrm{D}=11.5 \mathrm{~mm}$. Two types of noncohesive, spherical particles were used in the experiments $\left(500-600 \mu \mathrm{m}, 1500 \mathrm{~kg} / \mathrm{m}^{3}\right)$ and $(630-850 \mu \mathrm{m}, 1150$ $\left.\mathrm{kg} / \mathrm{m}^{3}\right)$. The particles were added to the source fluid to a volumetric concentration of about $0.1 \%$.

Lee [13] has performed experiments of horizontal sediment buoyant and non buoyant jets discharged in stationary ambient water. The bottom deposition rate of different jet flow rates, particle sizes and densities for jets were measured with bottom tray collection. The particle concentration across the jet cross sections of jets was measured by both the direct suction sampling technique and particle imaging technique. The settling velocities of particles were measured by the settling column experiments and compared with the settling formula using the size measurement from the Laser Diffraction Particle size Analyzer. The jet velocity field was checked by Laser Doppler Anemometry measurement. The experiments of horizontal jets in stationary ambient water were carried out in a $1 \mathrm{~m}$ long $\mathrm{x} 1 \mathrm{~m}$ width $\times 0.5 \mathrm{~m}$ high water tank. A constant water depth of roughly $0.45 \mathrm{~m}$ is maintained. The jet exit from a nozzle (6 $\mathrm{mm}$ diameter) with a flow ranged between 10 and $100 \mathrm{~L} /$ hour. In these experiments, freshwater is used as ambient fluid and ethanol-water mixture to produce the buoyancy jet. A wide range of particle size and density of spherical glass particles $\left(d_{50}=115-215, \mu \mathrm{m}, \rho_{p}=\right.$ $\left.2500 \mathrm{~kg} / \mathrm{m}^{3}\right)$ and synthetic particles $\left(d_{50}=621\right.$ and $716 \mu \mathrm{m}, \rho_{p}=1140$ and $\left.1160 \mathrm{~kg} / \mathrm{m}^{3}\right)$ are used to perform these experiments.

Table 2 shows the calculation details for all of the simulated experiments. We can see that the deposition criterion is satisfied after a trajectory less than one millimeter for all the experiments due to the abrupt loss of initial quantity of movement, once the discharge comes in contact with ambient water. 
Table 2. The simulation details and results for the experiments of Lane-Serff and Moran [9], Cuthbertson and Davies [10], and Lee [13] used to validate the proposed model.

\begin{tabular}{|c|c|c|c|c|c|c|c|c|c|}
\hline \multirow[b]{2}{*}{ Case } & \multirow[b]{2}{*}{$\begin{array}{c}\text { Data } \\
\text { source }\end{array}$} & \multirow[b]{2}{*}{$\begin{array}{c}\Delta \mathrm{t} \\
\left(10^{4} \mathrm{~s}\right)\end{array}$} & \multicolumn{5}{|c|}{ The deposition starts at } & \multirow[b]{2}{*}{$\begin{array}{c}w_{s 0} \\
(\mathrm{~m} / \mathrm{s})\end{array}$} & \multirow[b]{2}{*}{$\begin{array}{l}\text { Total } \\
\text { Depo } \\
\text { sition } \\
(\%)\end{array}$} \\
\hline & & & $\begin{array}{c}\text { Slice k* / } \\
\text { Total } \\
\text { slices }\end{array}$ & $\begin{array}{l}\mathrm{S}\left(10^{4}\right. \\
\mathrm{m}) / \text { the } \\
\text { entire } \\
\text { trajector } \\
\mathrm{y}(\mathrm{m})\end{array}$ & $\begin{array}{c}\mathrm{V}_{\mathrm{k}^{*}} / \\
\mathrm{V}_{0} \\
(\%)\end{array}$ & $\begin{array}{l}\emptyset_{k^{*}} \\
\left(^{\circ}\right)\end{array}$ & $\begin{array}{l}\alpha \mathrm{V}_{\mathrm{k}^{*}} \\
(\mathrm{~m} / \mathrm{s})\end{array}$ & & \\
\hline 1 & {$[10]$} & 5.53 & $209 / 249$ & $2.05 / 1.21$ & 35 & 1.22 & 0.03 & 0.03 & 94.0 \\
\hline 2 & [9] & 3.47 & 99/171 & $1.2 / 0.44$ & 48.0 & 13.94 & 0.028 & 0.027 & 89.0 \\
\hline 3 & [10] & 5.34 & $250 / 285$ & $1.98 / 1.49$ & 34.45 & 1.29 & 0.03 & 0.03 & 80.0 \\
\hline 4 & [13] & 3.50 & $179 / 599$ & $1.15 / 0.8$ & 38.38 & 0 & 0.027 & 0.026 & 99.9 \\
\hline 5 & [13] & 3.95 & $281 / 599$ & $0.945 / 0.8$ & 31.50 & 0 & 0.019 & 0.019 & 99.4 \\
\hline
\end{tabular}

The results obtained with the present model for horizontal buoyant jets in stationary ambient are shown in Figure 4. They are compared to data issued from experiments of Cuthberson and Davies [10]. A good agreement between the experimental data corresponding to case 1 in tables and the model is clear, where the majority of solid particles deposit in the nearfield (97 $\%)$. The deposition in the near field is the dominant mechanism in this case.

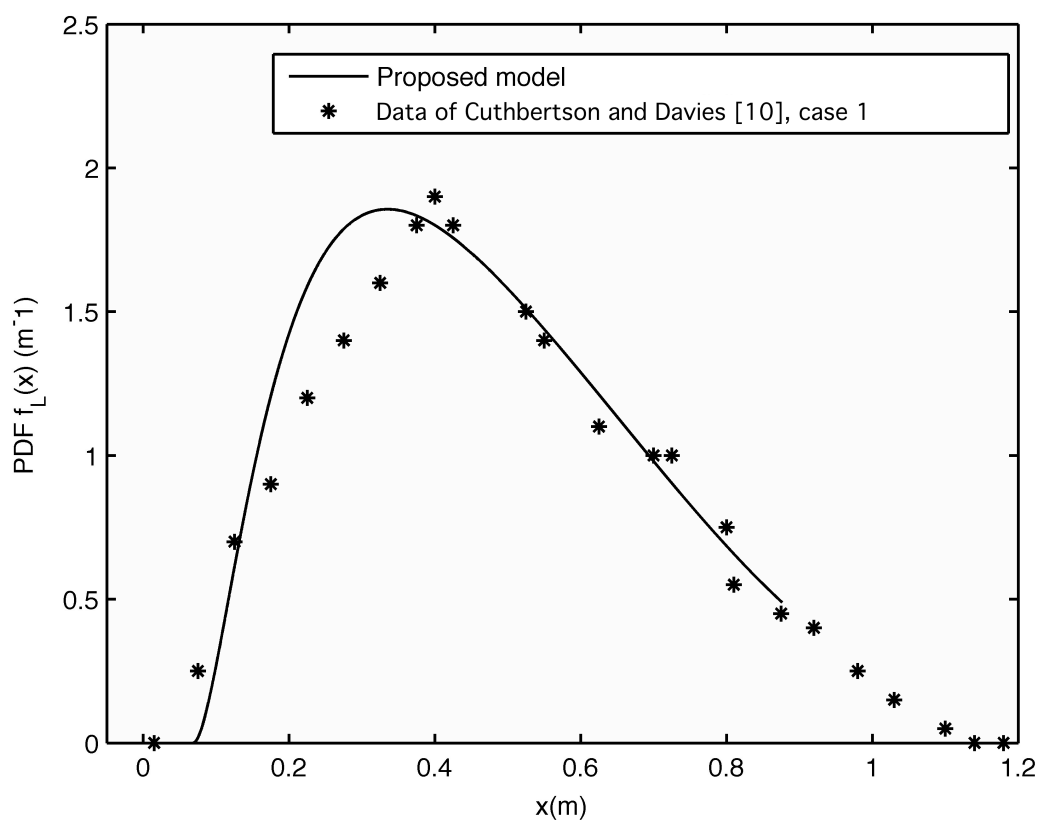

Figure 4. Model validation using data of Cuthbertson and Davies [10] for case 1 corresponding to the category of horizontal buoyant jets in stationary ambient.

Figure 5 shows the model results for inclined buoyant jets in stationary ambient. In this case, we note an acceptable agreement between the model and the experimental data obtained by Lane-Serff and Moran [9] corresponding to case 2 in tables. This agreement can be explained by the longer trajectory of jet before reaching the free surface (as the jet is inclined down) so the deposition in the nearfield is a dominant mechanism in a considerable part of the jet before approaching the free surface and the development of the surface gravity current. The difference between calculated values and measured values is probably because of the initial jet inclination towards the bottom, then change of direction towards the surface which creates 
a stagnant zone in the inferior part of the jet enhances the deposition. Another reason for this this difference is the possible interaction between the jet and the bottom of the tank.

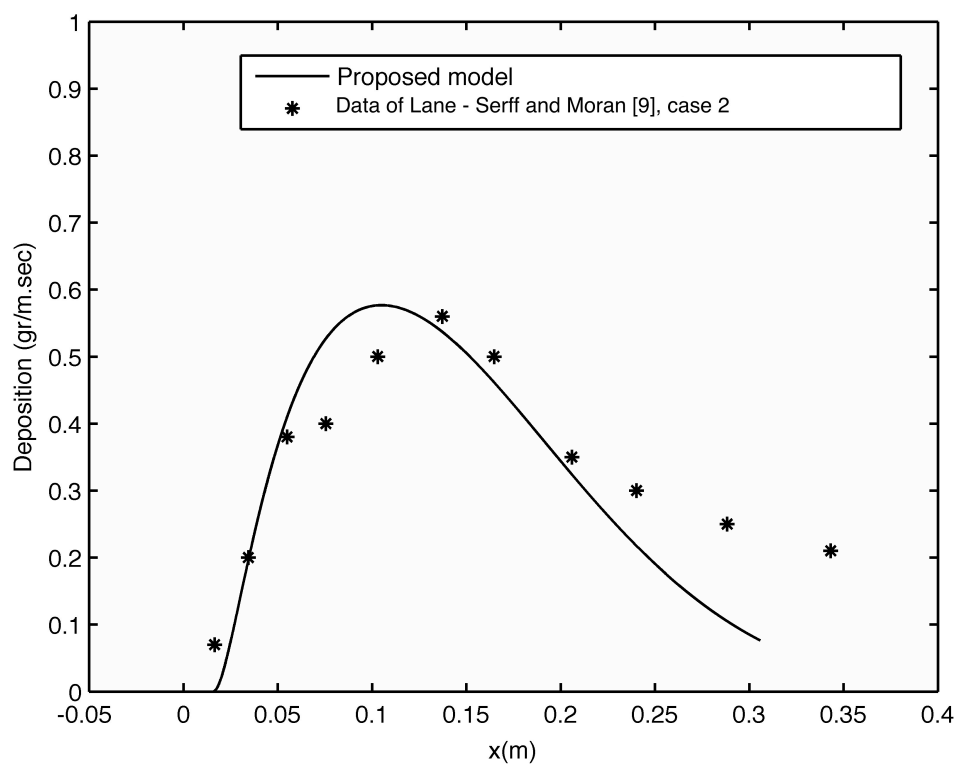

Figure 5. Model validation using data of Lane-Serff and Moran [9] for case 2 corresponding to the category of inclined buoyant jets in stationary ambient.

Figure 6 shows the model results for buoyant jets in a weak coflow compared to experimental data of Cuthberson and Davies [10] corresponding to case 3 in Tables. We see a good agreement between the data and the model even if the deposition rate peak was higher in our model. This is probably because the model underestimates the effect of ambient current or because the settling velocity in the presence of ambient current was in reality a little slower than the value reported in the reference. However, we can see that the deposition from nearfield is the dominant mechanism with $96 \%$ of solid particles deposited in the near-field.

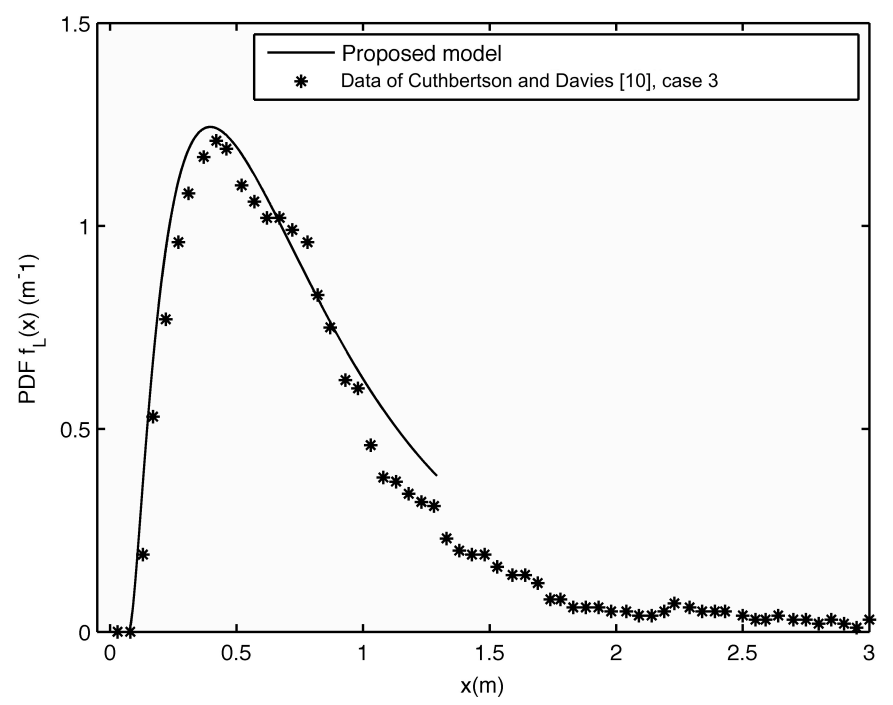

Figure 6. Model validation using data of Cuthbertson and Davies [10] for case 3 corresponding to the category of horizontal buoyant jets in presence of co-flow. 
The model proposed seems to predict well the deposition of sediments in the case of horizontal non buoyant jet moving in stationary ambient water, and transporting particles with small diameter and large density $\left(d_{50}=115,215 \mu \mathrm{m}, \rho_{p}=2500 \mathrm{~kg} / \mathrm{m}^{3}\right)$ such as represented in case 4, Figure 7. The model also calculates accurately the sediment deposition of particles with large diameter and small density $\left(d_{50}=621\right.$ and $716 \mu \mathrm{m}, \rho_{p}=1140$ and $\left.1160 \mathrm{~kg} / \mathrm{m}^{3}\right)$ transported by horizontal non buoyant jet moving in stationary ambient water as represented in case 5 , Figure 8.

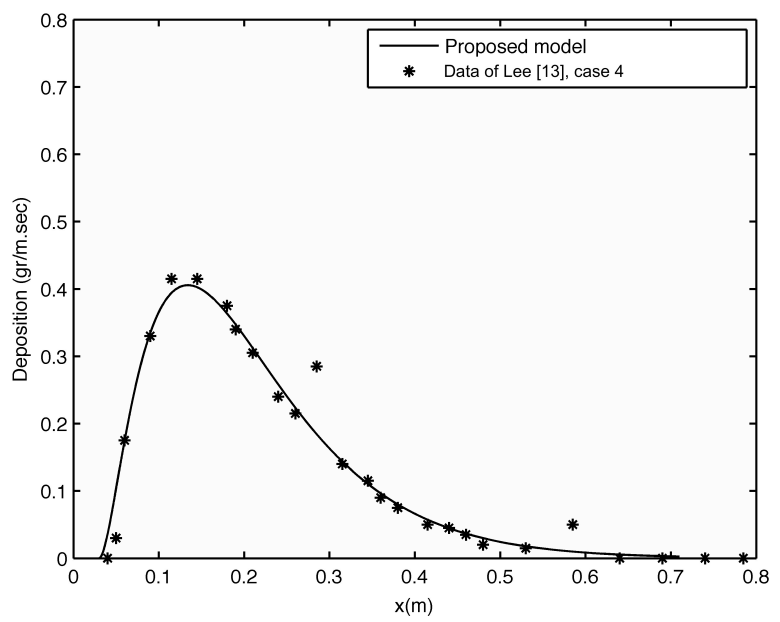

Figure 7. Model validation using data of Lee [13] for case 4 corresponding to the category of horizontal non-buoyant jets in stationary ambient for particles with small diameter and high density $\left(d_{50}=115,215 \mu \mathrm{m}, \rho_{p}=2500 \mathrm{~kg} / \mathrm{m}^{3}\right)$.

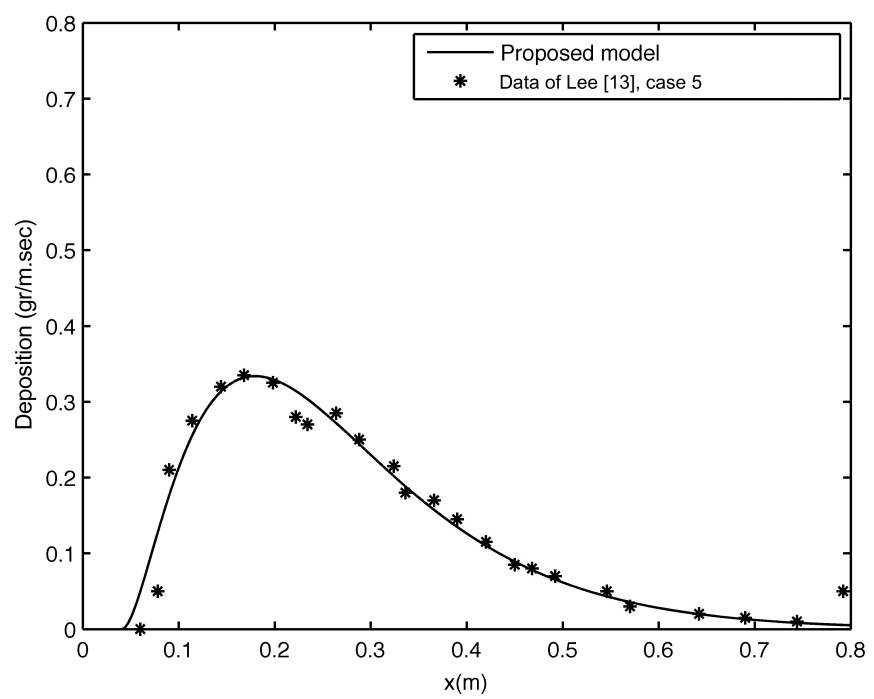

Figure 8. Model validation using data of Lee [13] for case 5 corresponding to the category of horizontal non-buoyant jets in stationary ambient for particles with large diameter and low density $\left(d_{50}=621\right.$ and $716 \mu \mathrm{m}, \rho_{p}=1140$ and $\left.1160 \mathrm{~kg} / \mathrm{m}^{3}\right)$.

Globally we see that the model is in good agreement with experimental data of the five cases studied in this paper. In the case of horizontal buoyant jets in stationary ambient, the importance of buoyancy forces that decrease the deposition in the near-field and naturally give more importance to the second stage of deposition from surface gravity currents. In the case of inclined buoyant jets in stationary ambient, the initial vertical velocity is negative and it increases slowly due to the buoyancy forces. A little difference between calculated values 
and measured values is noted, probably because of the initial jet inclination towards the bottom, which creates a stagnant zone in the inferior part of the jet.

For horizontal buoyant jet in coflowing ambient, the horizontal velocity is very close to the vertical velocity because of the presence of $u_{a}$ contrarily to all the previous experiments where the vertical velocity was always dominant in the last section and $u_{a}=0$. We see a good agreement between the data points and the model even if the deposition rate peak was higher in our model. This is probably because the model underestimates the effect of ambient current or because the settling velocity in the presence of ambient current was in reality a little slower than the value reported in the reference. The mechanism of deposition in the nearfield is the dominant mechanism in the majority of the studied cases.

\section{Conclusion}

Unidirectional coupling between the fluid mouvement and the sediment transport is successfuly performed in order to study the deposition from low-concentrated particle-laden turbulent jets in marine oufalls. A developed bidimensional lagrangian integral model is used in this study.

The deposition from each slice depends on the difference between two acting velocities, the first velocity, the particle settling velocity and the second velocity is the jet entrainment velocity. The deposition begins when the first velocity is greater than the second.

Laboratory experiments of Lane-Serff and Moran [9], Cuthbertson and Davies [10], and Lee [13] were selected from litterautre and used to validate the poposed model. The experiments consist of inclined and horizontal buoyant jets in stationary ambient, horizontal buoyant jet in coflowing ambient and nonbuoyant horizontal jet in stationary ambient. Globally, the model shows good agreement with experimental data especially when we have high deposition rates from the nearfield which makes the deposition mechanism studied here the dominant mechansim.

Experimental studies on more inclined jets seem indispensable in order to confirm the choice of deposition criterion. In addition to that, the integration of other mechanisms of deposition in the model like particles re-entrainment, deposition from surface gravity currents, the effect of confinement and the effect of surface waves in several scenarios are promising points at later steps of this work.

\section{References}

[1] Wasserman JC, Freitas-Pinto AAP, Amouroux D. 2000. Mercury concentrations in sediment profiles of a degraded tropical coastal environment, Env. Tech. 2000; 21; 3: 297-305.

[2] Ismail A, Ramli A. 1997. Trace metals in sediments and molluscs from an estuary receiving pig farms effluent, Env. Tech. 1997; 18; 5: 509-515.

[3] Perin G, Bonardi M, Fabris R, Simoncini B, Manente S, Tosi L, Scotto S. 1997. Heavy metal pollution in central venice lagoon bottom sediments : Evaluation of the metal bioavailability by geochemical speciation procedure, Env. Tech. 1997; 18; 6: 593-604.

[4] Degrémont and Suez. Memento Technique de l'Eau [Technical water memento], Lavoisier, 10th edition, France; 2005. 
[5] Neves MJ, Fernando HJS. 1995. Sedimentation of particles from jets discharged by ocean outfalls: A theoretical and laboratory study, J. Water Science and Techn. 1995; 32; 2: 133-139.

[6] Ernst GJ, Sparks RSJ, Carey SN, Bursik M I. Sedimentation from turbulent jets and plumes, J. Geoph. Res. 1996; 101(B3): 5575-5589.

[7] McLarnon CP. Sedimentation from a finite volume buoyant jet [dissertation], University of Dundee; 2001.

[8] Bleninger T, Carmer C. Sedimentation in Particle-Laden-Jets: Experimental and numerical study on sedimentation of suspended material from non-buoyant horizontal jets in unbounded ambient, Institutsbericht, Monographie, Institute for Hydromechanics, University of Karlsruhe, Germany; 2000.

[9] Lane- Serff GF, Moran TJ. Sedimentation from Buoyant jets, J. Hyd. Eng. 2005; 131; 3: 166-174.

[10] Cuthbertson AJS, Davies PA. Deposition from particle-laden, round, turbulent, horizontal, buoyant jets in stationary and coflowing receiving fluids, J. Hydr. Eng. 2008; 134; 4: 390-402.

[11] Li ACY. Theoretical modeling and experimental studies of particle-laden plumes from wastewater discharges [dissertation], Hong Kong: University of Hong Kong; 2006.

[12] Cuthbertson AJS, Apsley DD, Davies PA, Lipari G, Stansby PK. Deposition from particle-laden, plane, turbulent, buoyant jets, J. Hydr. Eng. 2008; 134; 8: 1110-1122.

[13] Lee WY. Mixing of horizontal sediment laden jets [dissertation], Hong Kong: University of Hong Kong; 2010.

[14] Hirst EA. Analysis of buoyant jets within the zone of flow establishment, Oak Ridge National Laboratory Report ORNL-TM-3470; 1971.

[15] Schatzmann M. The integral equations for round buoyant jets in stratified flows, J. Appl. Math. Physics. 1978; 29: 608-630.

[16] Davis LR. Fundamentals of Environmental Discharge Modeling, Mechanical and Aerospace Engineering Series (Book 10), 1st edition, CRC Press; 1999.

[17] Lee JHW, Cheung V. Generalized Lagrangian model for buoyant jets in current, J. Env. Eng. 1990; 116; 6: 1085-1105.

[18] Baumgartner DJ, Frick WE, Roberts PJW. Dilution models for effluent discharges, EPA/600/R-93/139; 1993.

[19] Jirka GH. Integral model for turbulent buoyant jets in unbounded stratified flows, Part I: Single round jet. Env. Fluid Mech. 2004; 4: 1-56.

[20] Lee JH, Chu VH. Turbulent jets and plumes. A Lagrangian approach, Kluwer Academic Publishers. 2003.

[21] Maxey MR, Riley JJ. Equation of motion for a small rigid sphere in a non-uniform flow, Physics of Fluids. 1983; 26: 883-889.

[22] Eaton JK, Fessler JR. Preferential concentration of particles by turbulence, Int. J. Multiphase Flow; 1994; 20: 169-209.

[23] Oesterlé B. Ecoulements multiphasiques; des fondements aux méthodes d'ingénierie [Multiphase flows; from fundamentals to engineering methods], Lavoisier, Paris, 2006. 
[24] Monchaux R, Bourgoin M, Cartellier A. Analyzing preferential concentration and clustering of inertial particles in turbulence, Int. J. Multiphase Flow. 2012; 40: 1-18.

[25] Bush JWM, Thurber BA, Blanchette F. Particle clouds in homogeneous and stratified environments, J. Fluid Mech. 2003; 489: 29-54.

[26] Koh RCY, Chang YC. Mathematical model for barged ocean disposal of wastes, Environmental Protection Technology Series EPA 660/2-73-029, U.S. Army Engineer Waterways Experiment Station, Vicksburg. 1973

[27] Johnson BH. User's guide for models of dredged material disposal in open water, Technical Report No. D-90-5, U.S. Army Engineer Waterways Experiment Station, Vicksburg. 1990.

\section{Nomenclature}

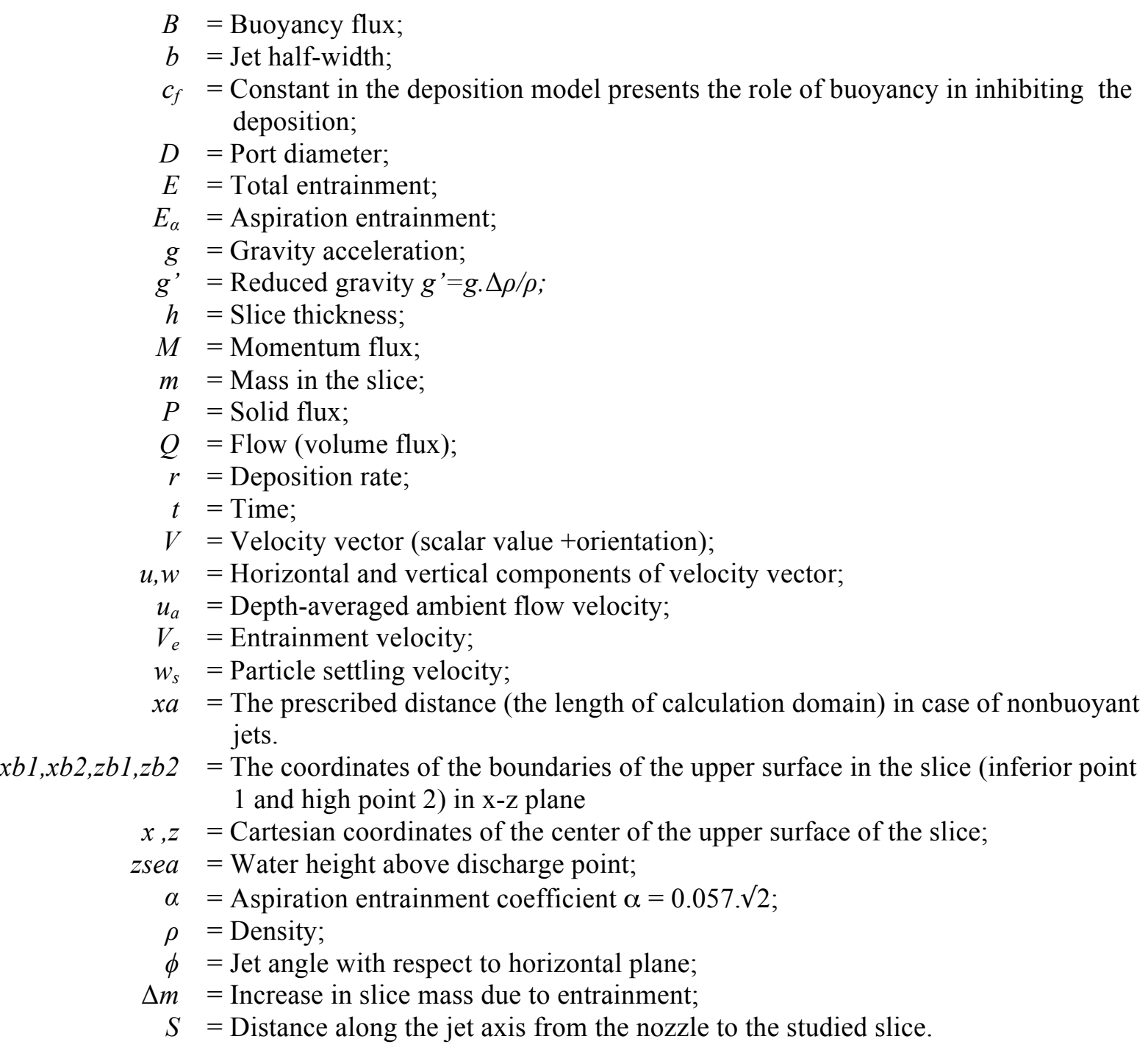

\section{Subscripts}

$0=$ Values at jet discharge point;

$a$ = Ambient values;

$k=$ Values of plume element at $k^{\text {th }}$ step of calculation. 